\title{
Aquisição de Sentenças Matrizes Infinitivas no Português Brasileiro em uma Criança de 20-24 Meses*
}

\author{
(Acquisition of Infinitive Matrix Sentences in Brazilian \\ Portuguese in a 20-24-month old Child)
}

\section{Sanir da ConceIÇão (PG - Universidade Federal de Santa Catarina)}

\begin{abstract}
This paper conducts an analysis of infinitive matrix sentences in Brazilian Portuguese in a 20-24-month period. The bypothesis is that children's grammar has the functional categories, as proposed by the continuist approach. However, Agr bas not been triggered with all its relevant features. This study considers that in children's Brazilian Portuguese, it is weak, as proposed by Galves (1993).

KEY-WORDS: infinitive sentence; functional category; continuist bypothesis.
\end{abstract}

RESUMO: Neste estudo, fazemos a análise das sentenças matrizes infinitivas do PB em uma criança no período de 20-24 meses. Levantamos como hipótese que, nesta fase, a gramática infantil tem as categorias funcionais, conforme aponta a corrente continuísta. Porém, Agr não foi acionado ainda com todos os traços relevantes. Consideramos que no PB infantil, ele é fraco, como proposto por Galves (1993).

PALAVRAS-CHAVE: sentença infinitiva; categoria funcional; hipótese continuísta.

\section{Introdução}

No quadro da Teoria de Princípios e Parâmetros, assume-se que as sentenças contêm categorias funcionais, que são não-lexicais, como D, C,

\footnotetext{
* Agradeço à profa. Dra. Ruth E. V. Lopes (UFSC) pela dedicação e orientação prestada no decorrer da elaboração deste artigo, que fez parte do meu processo de qualificação em aquisição da linguagem, no Curso de Doutorado em Lingüística da Universidade Federal de Santa Catarina. Agradeço também aos professores Drs. Sérgio Menuzzi (PUC/RS) e Ronice M. Quadros (UFSC) pela leitura deste texto e valiosas sugestões. Desnecessário dizer que possíveis erros são de minha inteira responsabilidade.
} 
T e $\operatorname{Agr}^{1}$ (Ver Chomsky, 1995). A introdução destes elementos na teoria sintática tem repercussão na teoria de aquisição da linguagem. Se a gramática adulta tem categorias funcionais, estas podem ou não estar disponíveis na gramática inicial. Duas hipóteses de aprendizagem apresentam pontos de vista diferentes: a hipótese maturacional e a hipótese continuísta.

De acordo com a hipótese maturacional, a gramática inicial pode apresentar propriedades únicas, diferentes da gramática adulta. Alguns autores, como Guilfoyle \& Nooman (1988), Meisel (1994), Radford (1990, 1997), propõem que as categorias funcionais não se projetam na gramática inicial. As pesquisas indicam que a ausência ou o uso limitado de morfemas associados a uma determinada categoria funcional são evidências para a sua não representação gramatical. Conforme Radford (1990, 1997), por exemplo, a gramática apresenta, no estágio inicial, apenas projeções de categorias lexicais como AP, NP, VP e PP.

Radford (1997) argumenta que as estruturas sintáticas encontradas no inglês infantil (20-24 meses de idade) diferem das encontradas no inglês dos adultos. Assim, as sentenças dos adultos são projeções de núcleos lexicais e funcionais, enquanto a estrutura das sentenças das crianças são projeções de quatro núcleos lexicais $(\mathrm{N}, \mathrm{V}, \mathrm{A}, \mathrm{P})$.

Em outras palavras, as estruturas dos adultos apresentam relações de redes temáticas e não-temáticas ao passo que as estruturas infantis apresentam apenas relações temáticas. $\mathrm{O}$ autor assume então que as primeiras estruturas das crianças que adquirem o inglês são de natureza léxico-temática. Portanto, temos duas estruturas diferentes, uma para adulto e outra para criança, respectivamente:

(1) a. $\complement_{I P} \complement_{D P}$ The doggy $\complement_{I}$ will $\complement_{V P} \complement_{V}$ bite $\left.] H\right]$

b. $\complement_{\mathrm{VP}}\left[_{\mathrm{NP}}\right.$ Doggy $\mathrm{L}_{\mathrm{V}}$ bite $\left.]\right\}$

$\mathrm{O}$ autor argumenta que as sentenças produzidas pelas crianças nesse estágio correspondem a mini-orações (small clauses) dos adultos.

\footnotetext{
1 Chomsky (1995) reduz as categorias funcionais àquelas que tem interpretação em LF. Como agreement (Agr), para ele, é uma relação e não tem interpretação independente, não encabeça uma categoria, reduzindo-se a uma coleção de traços. Neste trabalho, porém, consideraremos Agr como uma categoria funcional, assim como T, C e D.
} 
Rizzi (1994), analisando as sentenças matrizes infinitivas infantis, propôs que elas fossem analisadas como estruturas truncadas. Estas sentenças são geradas abaixo de TP. Segundo o autor, isto acontece porque um princípio não está operativo:

(2) $\mathrm{CP}=\operatorname{root}$

De acordo com Rizzi, todas as estruturas iniciam-se com CP. Porém, ele não está operativo no início da aquisição. Por esse motivo, há possibilidade de se construirem estruturas com sujeito nulo mais infinitivo em sentenças matrizes em todas as línguas no período de aquisição. Quando, porém, CP se torna operativo, tais estruturas não são mais permitidas. Por exemplo, no inglês, quando um sintagma-Wh em Comp é produzido, não são mais possíveis estruturas com sentenças matrizes infinitivas. Todavia, a proposta de Rizzi (1994) difere da de Radford (1990, 1997) ao não assumir que as categorias funcionais estão ausentes na gramática inicial.

Em contraste com a hipótese maturacional, a hipótese continuísta assume que a gramática inicial é formada pelas mesmas categorias e princípios de uma gramática adulta. Pinker (1984, apud Meisel 1997:23), o primeiro proponente da hipótese, diz:

As regras gramaticais da criança devem ser extraídas dos mesmos tipos básicos de regras e compostas de símbolos primitivos da mesma classe, como as regras gramaticais atribuídas aos adultos. (p.7)

A hipótese continuísta apresenta duas versões: a forte e a fraca. $\mathrm{Na}$ versão forte, argumenta-se que a gramática inicial contém todas as categorias funcionais, independentemente de os morfemas associados a elas aparecerem ou não na produção infantil. Desta forma, o conhecimento sobre as categorias funcionais na gramática infantil corresponde ao da gramática adulta, pois elas estão disponíveis.

A versão fraca da hipótese continuísta assume que há estados diferentes para a gramática infantil, mas que não ferem a Gramática Universal. Segundo seus proponentes, as restrições encontradas na gramática infantil podem estar relacionadas às dificuldades de processamento, à falta de memória, por exemplo. Clahsen (1989:57) apresenta a hipótese de aprendizagem lexical em que diz: 
Given the lexical learning bypothesis, it is possible that, while all of the UG principles are ready to apply from the start, some must await the acquisition of certain lexical triggers, before they can be successfully used.

Conforme Clahsen, alguns princípios ou categorias funcionais só podem "aparecer" quando a criança tiver identificado/adquirido um determinado item lexical que acionará tal categoria. Assim, as mudanças encontradas na gramática infantil ocorrem como resultado do aumento do léxico, além do aumento no tamanho da memória e da capacidade de processamento.

Lopes (2001:125) sugere que esta hipótese ganha força explicativa porque lida com fenômenos que "parecem não ter uma mudança abrupta - como se esperaria se fosse o caso de um determinado princípio e/ou categoria amadurecer -, além de também conseguir explicar discrepâncias que surgem entre a produção infantil e a adulta”.

A partir dos pressupostos teóricos da hipótese continuista, fazemos a análise das sentenças matrizes infinitivas do $\mathrm{PB}$ em uma criança no período de 20-24 meses. Levantamos como hipótese que, nesta fase, a gramática infantil tem as categorias funcionais, conforme aponta a corrente continuista (Pinker 1984, Kato 1995). Porém, Agr não foi acionado ainda com todos os traços relevantes. Consideramos que no PB infantil, ele é fraco, como proposto por Galves (1993).

O trabalho está assim estruturado. Na primeira seção, apresentamos os dados coletados e os critérios utilizados. Na seção 2, descrevemos os dados de uma criança no período de 20-24 meses e os contrapomos à proposta de Radford (1997). Nosso trabalho enfoca principalmente a categoria IP, que, assumimos, se divide em T e Agr, conforme Pollock (1989) ${ }^{2}$. Nossos dados apontam que no período que se caracteriza pela ocorrência de sentenças infinitivas há também a ocorrência de sentenças finitas.

Na seção 3, analisamos a proposta de Wexler (1998), levando em consideração Chomsky (1995) no que diz respeito a traços formais $[ \pm$ interpretáveis]. Nesta seção também tentamos dar uma explicação para a

\footnotetext{
2 Não entraremos aqui na questão de qual categoria domina a outra, pois isto não é relevante para nossa análise, como veremos adiante. Ver Pollock (1989) e Belletti (1990), que discutem esta questão.
} 
aquisição de sentenças infinitivas no PB a partir da análise dos dados, propondo que neste período Agr é fraco, conforme Galves (1993). Porém, não assumimos que Agr seja fraco para o PB adulto. Propomos, para o período analisado, que Agr é fraco porque o sistema verbal da criança é unipessoal, como proposto por Kato (2001). Desta forma, nem todos os traços relevantes de Agr foram adquiridos.

\section{Dados}

O corpus selecionado para este trabalho faz parte das amostras de fala de uma criança (R.) estudada dos 20 aos 24 meses $^{3}$. Fizemos uma análise quantitativa, tendo em vista a seguinte questão: com que freqüência uma criança, no estágio inicial de aquisição do PB, usa sentenças matrizes infinitivas?

Encontramos 555 sentenças matrizes finitas e infinitivas. Destas, 67 foram analisadas como imperativas. Não as incluímos na análise porque alguns autores, como Kato (1995), postulam que elas apresentam uma estrutura diferente, isto é, não apresentam a categoria funcional AspP, ao passo que as outras apresentam. Esta questão não será discutida aqui e por isso preferimos exclui-las da análise. Então, num total, foram analisadas 488 sentenças no período de 20 a 24 meses. Vejamos a tabela abaixo:

Tabela 1 - Quantidade de sentenças em cada período

\section{SENTENÇAS}

\begin{tabular}{c|c}
\hline Idade $^{4}$ & Total \\
\hline $1 ; 8$ & 78 \\
\hline $1 ; 9$ & 111 \\
\hline $1 ; 10$ & 71 \\
\hline $1 ; 11$ & 31 \\
\hline $2 ; 0$ & 197 \\
\hline $\begin{array}{c}\text { Total de } \\
\text { contextos }\end{array}$ & 488 \\
\hline
\end{tabular}


As sentenças analisadas são matrizes e declarativas, como em:

(3) a. A vê tinta $(1 ; 09,08)$

b. Pecija pegá o porquinho, a galinha $(2 ; 00,20)$

Sentenças como

(4) M: Deixa a fita, deixa a fita ${ }^{5}$

R: Dessa

não foram computadas pelo fato de serem consideradas meras repetições da fala adulta. As sentenças repetidas sem serem questionadas também foram desconsideradas. Vejamos:

(5) M: Pronto

R: Caiu

Ota caiu

Caiu

Caiu

Apenas a primeira sentença Caiu foi considerada. As outras não foram contadas. Todavia, quando questionadas, todas entraram na quantificação:

(6) R: Potá

M: Quê?

R: Potá

M: Ahn?

R: A potá

Neste caso, foram computadas três sentenças infinitivas.

Alguns verbos flexionados, usados como respostas, também foram considerados. Por exemplo:

5 A letra $M$ refere-se à mãe da criança e $R$, à criança. 
(7) a. M: Cê gosta da Kelly?

R: Gótu ${ }^{6}$ (Gosto) $(1 ; 8,25)$

b. M: Cê tirou o popô?

R: Tilô (Tirou) $(1 ; 9,20)$

Mas as respostas com o verbo flexionado é foram desconsideradas:

(8) M: Já tem dois aí. Cê quer que eu pegue mais popô?

$\mathrm{R}: \mathrm{E}^{7}$

\section{Análise de Radford (1997) e os Dados do PB}

Nesta seção, descrevemos os dados do $\mathrm{PB}$, indicando a disponibilidade das categorias funcionais DP, CP e IP na gramática infantil, no período de 20-24 meses. Observaremos inicialmente as categorias funcionais DP e $\mathrm{CP}$, de forma geral, e enfocaremos, em seguida, a categoria funcional IP, nosso objeto de estudo que, pressupomos, nos dará "pistas" sobre a aquisição de sentenças infinitivas.

Começamos nosso argumento com o sistema DP porque pretendemos mostrar que a hipótese de Radford (1997), sobre um período léxico-temático, anterior ao funcional, não condiz com os dados do PB. Radford propõe que as primeiras estruturas nominais produzidas pela criança não possuem um sistema DP projetado. Segundo o autor, a ausência de artigos, de demonstrativos ou do genitivo 's, mostra que a gramática infantil possui apenas a categoria lexical NP.

Observamos em nossos dados que a criança produz, no período de 2024 meses, nome em que não aparece o determinante, como em:

(9) Catinha (Plantinha) $(1 ; 08,0)$

\footnotetext{
6 Não nos esqueçamos de que no PB usamos como resposta a perguntas sim/não o verbo flexionado, isto é, elipse de VP com sujeito nulo. Para mais detalhes ver Kato (1999).

7 Seria necessário fazer um estudo sobre estes tipos de respostas. Provavelmente, essas sentenças não têm a mesma estrutura que os de (7).
} 
Porém, para o $\mathrm{PB}$, é possível que em determinados contextos, os nomes sejam acompanhados por determinante ou não. É comum, de acordo com Palmieri (1998), a criança ouvir expressões como: "Quero bala", em que o nome não é precedido por artigo. $O$ fato de se encontrar, na fala adulta, nomes sem artigo, não significa que não exista $\mathrm{DP}$. $\mathrm{O}$ que pode acontecer é que a posição $\mathrm{D}$ esteja vazia, não preenchida lexicalmente.

Encontramos também dados em que a criança produz nomes precedidos por determinante, como em (10):

(10) a. A boca $(1 ; 08,25)$

b. A balalão (O cavalão) $(1 ; 09,8)$

Dessa forma, podemos supor que a categoria funcional DP seja projetada no início da aquisição do PB.

Radford (1997) também mostra evidências no inglês para a ausência de CP. Uma delas é que as sentenças complemento das crianças não são formuladas com complementizadores that, for, if:

(11) Want [lady get chocolate] (Querer [mulher pegar chocolate]) / Eu quero que a mulher pegue chocolate. Daniel, 23 meses

$\mathrm{O}$ autor postula, assim, que as sentenças complemento das crianças assemelham-se a mini-orações (small clause) dos adultos ${ }^{8}$, que nunca são introduzidas por complementizador. Este fato, segundo o autor, levanta a hipótese de que as sentenças iniciais são destituídas de um sistema CP. Como a criança não apresenta ainda o sistema $\mathrm{CP}$, postula-se que ela não tenha também o especificador de CP. Portanto, ela não apresentará qualquer evidência de que adquiriu a regra de movimento-Wh do inglês dos adultos. $\mathrm{Na}$ fala dos adultos, os sintagmas Wh vão para a posição de especificador de CP, não-temático, à esquerda de CP. Isto, porém, não acontece com as sentenças infantis:

\footnotetext{
8 Kato (1995:120), contrária a Radford, propõe que falas iniciais da criança não são "miniorações", mas "estruturas sintáticas bem mais complexas que se referem a entidades e eventos."
} 
(12) Mummy doing? (What is mummy doing?) / O que mamãe está fazendo? Daniel, 21 meses

Klima \& Bellugi (1996, apud Radford (1997), sugerem que as crianças nesta fase freqüentemente não conseguem entender perguntas com Wh movido, como por exemplo, What are you doing? (O que você está fazendo?). Radford então assume que, na fase léxico-temática, pelo fato de a criança não possuir o sistema $\mathrm{CP}$, ela não consegue analisar os constituintes do CP adulto.

Constatamos, porém, que, no $\mathrm{PB}$, a criança consegue responder e interpretar interrogativas do tipo sim/não e interrogativas-Wh movidas de forma coerente:

(13) a. M: Quer ligar?

R: Quelu $(1 ; 08,0)$

b. M: Onde que o papai tá?

R: A sala $(1 ; 08,25)$

c. M: Que que cê tá fazendo?

R: Tô pintandu $(1 ; 09,08)$

Como podemos observar, em (13a), temos interrogativa sim/não; em (13b-c) temos perguntas-Wh movidas, sendo o adjunto adverbial alçado em (13b) e o objeto alçado em (13c). Kato (1995) supõe que CP esteja representado em LF, embora a criança ainda não tenha os mecanismos de "spell-out" dessa categoria em PF.

Com relação à IP, Radford (1997) argumenta que, no inglês adulto, os verbos auxiliares não-modais como do/have/be, conforme Pollock (1989), são gerados em VP e se movimentam para IP. Porém, nas primeiras construções da criança estes elementos não aparecem, indicando a ausência do sistema IP. Vejamos:

(14) Mummy doing dinner ( Mummy is doing the dinner) / Mamãe está preparando o jantar Daniel, 22 meses

Para o PB, assumimos, conforme Pollock (1989), que a categoria funcional IP se divide em TP e AgrP. Assumimos também que o verbo, inde- 
pendentemente de ser lexical ou não, de acordo com Figueiredo Silva (1996), se movimenta em sintaxe visível. No período de 20-24 meses, encontramos sentenças negativas como:

(15) Você um vai $(1 ; 10,23)$

Segundo Pollock (1989), a categoria funcional NegP é uma categoria máxima independente, situada entre as projeções funcionais TP e AgrP, isto é, acima de VP. Supomos então que o DP você, em (15), sobe para Spec de uma categoria funcional, seja TP ou Agr. Para o PB, assumimos que o verbo se movimenta para o núcleo de TP.

Todavia, no mesmo período que a gramática infantil dispõe das categorias funcionais DP, CP e TP, a criança produz sentenças infinitivas como em:

$\begin{array}{lll}\text { (16) a. Popô pacá (Popô pegar) } & (1 ; 08.0) \\ \text { b. Foná (Telefonar) } & (1 ; 08.0) \\ \text { c. Fuá (Fumar) } & (1 ; 08.25) \\ \text { d. Enessê aleia (Encher de areia) } & (1 ; 08,25)\end{array}$

Kato (1995) postula que neste período não temos ainda nem Tempo nem Agr. O que se tem, na verdade, é um T com núcleo default ${ }^{10}$ Presente. Esse $\mathrm{T}$ default licencia o núcleo aspectual (AspP) em que temos verbos como, em (16), de sentenças infinitivas, ou verbos de sentenças finitas, como "quero" (1;08,0), "caiu" $(1 ; 08,0)$, por exemplo.

Segundo a autora, enquanto não tivermos contraste temporal (presente $x$ passado), e a aquisição da morfologia de pessoa, que é um processo visível pela redundância pronominal, T não terá como núcleo [Presente] ou [Passado]. Os nossos dados mostram que é a partir de 1;10 meses que aparecem simultaneamente $\mathrm{T}$ de uma forma flexional para Tempo, como em:

\footnotetext{
9 A presença de auxiliar também indica presença de TP.

10 A autora postula que a criança conte, no início, apenas com a noção Reichenbachiana de Tempo do Ato da Fala (ST), sem contar ainda com o Tempo de Evento (ET), e que o Tempo de Referência (RT) sempre coincide com o ST.
} 


$\begin{array}{lll}\text { (17) a. Azudei } & (1 ; 10,23) \\ \text { b. Fis sissi } & (1 ; 11,3) \\ \text { c. Peguei } & (2 ; 00,20) \\ \text { d. Bate } & (1 ; 11,3) \\ \text { e. Num pode } & (1 ; 11,3) \\ \text { f. Abi (abre) } & (2 ; 00,05)\end{array}$

(17a-c) apresentam o tempo verbal passado e (17d-f) apresentam o tempo verbal presente. Assumimos então que é a partir de 1;10 meses que a gramática infantil de nosso sujeito constitui-se da categoria funcional TP com núcleo [Presente] e [Passado]. Anteriormente a este período, assumimos que há uma categoria funcional com TP, mas este apresenta núcleo default Presente.

Consideremos agora (18):

(18) a. M: Onde cê vai? Vai na escola?

R: Vai. $\quad(1 ; 09,8)$

b. A qué tilá tijama (Eu quero tirar pijama) $\quad(1 ; 10,23)$

Em (18), tanto em resposta a uma pergunta (18a), como em sentença matriz (18b), há violação da concordância de pessoa. Levantemos, então, como hipótese, que a gramática infantil não tenha acionado ainda a categoria $\mathrm{Agr},{ }^{11}$ com todos os traços relevantes ${ }^{12}$.

Ingham (1998) assume que a gramática infantil inglesa, no período de 2;06 a 2;09 meses, apresenta TP mas não Agr. O autor, primeiramente, mostra evidências de que existe categoria funcional neste período. Um exem-

\footnotetext{
11 Meisel (1994) prediz que o tempo vem depois da concordância (Agr). O autor assume que a categoria INFL (flexão) é substituída por Agr, Tempo e Finitude. Para o PB esta hipótese não se confirma, pelo menos aparentemente, conforme Lopes (1999:59, nota 4), porque no processo de aquisição a criança não usa sentenças infinitivas flexionadas, o que era de se esperar caso tivéssemos Agr antes de T. Vejamos:

(i) Fonarem (telefonarem)

Em nenhum momento constatamos construções infantis que apresentem Agr sem T.

12 Rubino \& Pine (1998) mostram que a criança brasileira, na idade entre 3;02,07 e 3;04,08, apresenta discordância entre sujeito-verbo. Há casos em que a discordância de número para a $3 \underline{a}$ pessoa do plural, por exemplo, chega a 43,5\%. Porém, essa discordância diminui na última faixa etária analisada, indicando, para nós, que Agr é acionado.
} 
plo dado é o alçamento de sujeito, que fica mais claro quando temos a presença de um advérbio:

(19) Her (al)ready going in the bath (Dela já indo no banheiro) Sophia, 2;6 meses

Dada a existência de categoria funcional, Ingham afirma que a gramática infantil, neste estágio, é destituída de AgrP. A falta de concordância de $3^{\text {a }}$ pessoa do singular, /-s/, no presente, indica a sua ausência. $O$ autor analisou sentenças que ocorrem em contextos lingüísticos como o de (20a), em que a mãe retoma o enunciado da criança, e em contextos nãolingüísticos como o de (20b), em que a mãe faz uma anotação referindo-se à situação:

(20) a. Criança: Tent. That look like a sausage (Barraca. Aquela parece uma lingüiça)

(2;7 meses)

Mãe: It does look like a sausage (Ela parece uma lingüiça)

b. Criança: Jack come Mary school (Jack alcança Mary na escola) (2;7 meses) [Nota da mãe: "Pres. 3"]

Em nenhum desses contextos a criança faz a concordância de $3^{\underline{a}}$ pessoa do singular.

Os contextos com sentenças negativas e interrogativas também não apresentam concordância de $3^{\underline{a}}$ pessoa do singular. Consideremos apenas a sentença negativa:

(21) My baby don't feel well (My baby doesn't feel well) / Meu bebê não se sente bem

Já para confirmar que a gramática infantil apresenta TP, o autor apresenta o uso do auxiliar do em elipse de VP:

(22) a. Criança: Me do not time Sophie, 2;7

b. Mãe: You haven't done anything (Você não fez nada)

Criança: Yes, me did (Sim, eu fiz) $(2 ; 7)$

A distribuição de do e did segue as linhas da referência temporal de passado versus presente. Logo, o autor postula que TP é projetado. 
Para o PB, assumimos que Agr não seja acionado na gramática infantil no período de 20-24 meses porque é fraco. Galves (1993:395) propõe que o elemento de concordância do PB é fraco. A autora define "fraco" da seguinte maneira:

(23) ... é fraca a concordância que não contém pessoa, ou contém pessoa como um traço puramente sintático. É o que acontece no $P B$ onde não se encontra na flexão verbal a

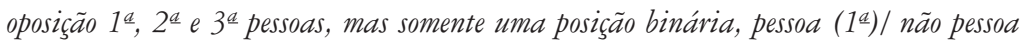
(3a), articulada a uma oposição singular/plural.

Segundo a autora, a não-oposição $1^{\mathrm{a}}, 2^{\underline{a}}$ e $3^{\underline{a}}$ pessoas corresponde a uma concordância fraca morfológica e semanticamente. Morfológica devido à ausência de 2 a pessoa e semântica porque há possibilidade de se interpretar a $3^{\mathrm{a}}$ pessoa do singular como indeterminada. Galves (1993: 396) propõe que o morfema de concordância fraco não seja gerado em um núcleo independente, mas como afixo de T. ${ }^{13}$

Para esse trabalho, assumimos que Agr não é acionado no período estudado e que portanto não se projeta. No entanto, após esse período, ele se projeta, sendo um núcleo independente, conforme proposto por Figueiredo Silva (1996). O que pode confirmar a hipótese de que no PB temos duas categorias independentes - TP e Agr - é a existência do infinitivo flexionado:

(24) É importante os garotos irem para a escola

Nessa sentença, há um elemento de concordância independente do morfema de tempo.

Assumimos que Agr será acionado quando a criança sair do sistema unipessoal. Kato (2001) assume que o sistema verbal inicial da criança brasileira é unipessoal, mesmo que se refira a pessoas distintas do discurso. Isso é possível, de acordo com a autora, porque os pronomes são formas de tratamento, inclusive a $1^{\underline{a}}$ pessoa. No $\mathrm{PB}$, a $2^{\underline{a}}$ pessoa indireta (você) é igual a $3^{\mathbf{a}}$, no que diz respeito à concordância. O pronome você é oriundo da

13 Segundo Galves (1993), um AgrP é projetado para que os tópicos fiquem em [Spec, AgrP]. 
forma de tratamento vossa mercê, que é nominal. Então nada impede que o sistema seja constituído de pronomes com natureza nominal, pois são formas de tratamento, assim como papai e mamãe. O sistema só passa de unipessoal para pluripessoal quando a criança aprende os pronomes fracos, que podem ser livres, clíticos ou afixos.

Com a descrição acima, temos algumas considerações a fazer. A primeira diz respeito à categoria funcional TP. Assumimos que TP está em uso pleno pela gramática infantil a partir de 1;10 meses, quando há contraste temporal. No período anterior a esse, as sentenças matrizes finitas e infinitivas têm a mesma estrutura e o mesmo comportamento, isto é, Agr não é projetado e $\mathrm{T}$ default Presente funciona como uma âncora temporal, conforme proposto por Kato (1995). Assim, os verbos de sentenças como "pegar", "quero" e "caiu" vão para o núcleo de AspP.

Quando TP apresenta os traços de [Presente] e [Passado], os verbos das sentenças:

- como "vou" e "ver", de sentenças finitas e infinitivas, respectivamente, têm os traços do verbo verificado em T, que têm núcleo [Presente];

- como "peguei", de sentenças finitas, têm os traços do verbo verificado em T, que têm núcleo [Passado].

Com relação à AgrP, assumimos que, no período de 20-24 meses, ele não é acionado, possibilitando assim a co-ocorrência de sentenças finitas e infinitivas. Como dito anteriormente, propomos que a concordância do PB é fraca, no início da aquisição, nos termos de Galves (1993). Embora tenhamos a presença de alguns morfemas de concordância, assumimos, com Kato (2001), que o sistema verbal da criança é unipessoal. Somente quando o sistema verbal unipessoal passar a pluripessoal Agr será acionado.

Na próxima seção, analisaremos a proposta de Wexler (1998) para a co-ocorrência de sentenças matrizes finitas e infinitivas em algumas línguas durante o período inicial da aquisição.

\section{Estágio do Infinitivo Opcional - Análise de Wexler (1998)}

Um estágio em que há co-ocorrência entre sentenças matrizes finitas e infinitivas também é comum em línguas como o inglês. Wexler (1998) 
chama este período de "estágio do infinitivo opcional". O autor observa que as gramáticas infantis que permitem a co-ocorrência de sentenças matrizes finitas e infinitivas também permitem o sujeito nulo, mesmo em línguas que são de sujeito não-nulo, como o inglês. Dada esta constatação, Wexler (1990), apud Wexler (1998), relaciona o estágio do infinitivo opcional com a produção de sujeito nulo. $\mathrm{O}$ autor observa que as sentenças matrizes infinitivas apresentam mais sujeito nulo (entre 70-95\%) do que as sentenças matrizes finitas (entre 15-30\%) em inglês. Contudo, as sentenças infinitivas podem ter a posição sujeito ocupada por um DP lexical assim como as sentenças finitas.

O autor pressupõe que no estágio do infinitivo opcional:

(25) a. Agr ou T podem ser projetados;

b. Agr verifica Nominativo. Se não há Agr, o sujeito recebe caso default, que no inglês é o acusativo; ${ }^{14}$

c. A ausência de T licencia PRO;

d. Agr domina T;

e. Agr e T têm um traço nominal (EPP) [não-interpretável].

A partir desses pressupostos, haveria dois tipos de infinitivo opcional na aquisição do inglês:

(26) a. [+Agr, $-\mathrm{T}]$ : He like ice-cream

b. $[-\mathrm{Agr},+\mathrm{T}]$ : Him like/liked ice-cream

Quando Agr está presente, o sujeito é nominativo, como em (26a); quando, porém, somente $T$ está presente, o sujeito recebe caso default, que no inglês é o acusativo, como em (26b). Um problema para a teoria do infinitivo opcional é o fato de o sujeito de uma sentença infinitiva subir. O que motiva a sua subida? Wexler (1998) assume, conforme Chomsky (1995), que o sujeito sobe para verificar EPP:

(27) EPP is the requirement that a D (Determiner) feature be checked (p. 50)

14 No PB, o caso default é o Nominativo, como proposto por Kato (2001). 
Em outras palavras, Agr e T tem um traço-D (EPP) que deve ser verificado pelo traço-D de um determinado DP (sujeito). O traço-D de Agr ou T é [não-interpretável] e por isso deve ser verificado. Então o sujeito sobe para verificar esse traço. Assim, Wexler assume que:

(28) Both Agr and T have a D feature ${ }^{15}$ which must be eliminated by checking against the D-feature of a DP which raises up for checking. (p. 51)

Uma sentença finita terá as seguintes derivações:

(29) a. Agrs[D] TNS[D] $\left.\sum_{\mathrm{VP}} \mathrm{DP} \quad \mathrm{V} \ldots\right]$

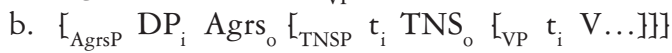

Em (29a), tanto Agr como T têm o traço-D. O sujeito sobe primeiramente para verificar o traço-D de T e depois, de Agr, como mostra (29b). Mas, para Wexler às vezes a gramática infantil permite sentenças como (26a) e (26b), tendo as estruturas (30a) e (30b), respectivamente:

(30) a. $\left.\quad \mathrm{NP}_{\mathrm{i}}[\mathrm{Nom}] \operatorname{Agr}[\mathrm{D}] \mathrm{L}_{\mathrm{VP}} \mathrm{t}_{\mathrm{i}} \mathrm{V} \ldots\right]$

b. $\mathrm{NP}_{\mathrm{i}}[\mathrm{Não}$ há caso atribuído $\left.] \mathrm{T}[\mathrm{D}] \mathrm{LVP}_{\mathrm{VP}} \mathrm{t}_{\mathrm{i}} \mathrm{V} \ldots\right]$

Em (30a), o traço-D de Agr faz com que o sujeito suba. Se T é projetado, como em (30b), o traço-D de $\mathrm{T}$ faz com que o sujeito suba. Mas como T não verifica caso, não há traço de caso que seja verificado por T e o caso default é realizado pela morfologia.

Dada a derivação de sentenças finitas em (29) e a possibilidade de estruturas como em (30), Wexler propõe que a gramática infantil apresenta uma restrição no sistema computacional:

(31) Restrição de Verificação Única

The D-feature of DP can only check against one functional category. (p. 59)

15 Para Wexler (1998), TP e Agr são categorias funcionais que têm traço-D forte. A força de um traço é um dos elementos da variação lingüística. Um traço formal pode ser forte ou não. Se for forte vai determinar movimento antes de Spell-out, em violação a Procrastinar. Para maiores detalhes, ver Chomsky (1995: 322). 
De acordo com o autor, o DP pode, na gramática infantil, ter um traço-D [interpretável] ou [não-interpretável]. Quando DP tem traços [nãointerpretáveis], uma única categoria funcional - Agr ou T - terá seu traço$\mathrm{D}$ verificado. Se isto acontecesse em uma estrutura em que ambos T e Agr estivessem presentes, a derivação implodiria, pois um traço-D não seria verificado. Por esse motivo, Wexler propõe que a gramática infantil projete uma única categoria funcional, Agr ou T, em que terá seu traço-D verificado pelo DP com traço [não-interpretável].

Em suma, Wexler propõe que a gramática infantil no estágio do infinitivo opcional tem Agr e T e que ambos têm traço-D forte e, por isso, há movimento visível nesse estágio. Mas apenas uma destas categorias pode ser projetada. $\mathrm{O}$ autor diz que isso acontece porque, às vezes, o traço-D de um DP é analisado como [não-interpretável] na gramática infantil. Sendo assim, o DP pode verificar apenas um traço-D, ou de T ou de Agr. Quando um dos traços é verificado, ele é apagado. Portanto o DP não pode verificar o outro traço-D. Então, a gramática infantil nesse estágio optará por uma única projeção: Agr ou T, em que apenas um traço-D será verificado.

A análise de Wexler levanta alguns problemas. O autor não discute, por exemplo, porque DP, inicialmente, tem traço [não-interpretável] e depois passa a ter traço [interpretável], como na gramática adulta. Nossa solução para este problema é a seguinte: propomos, nesse trabalho, que DP está presente na gramática infantil desde o início. E também que os pronomes são analisados como nomes, porque o sistema verbal da criança é unipessoal. Podemos dizer então que, nesse período, DP tem traço [nãointerpretável]. Quando, porém, a gramática passa a ser pluripessoal, isto é, quando adquirem os pronomes fracos, o DP passa a ter traços Łinterpretáveis].

Podemos dizer, assim, que a gramática infantil terá DP com traço [interpretável] a partir do momento em que Agr também for acionado. Quando isso acontecer, a gramática infantil não terá mais a opção de obter a co-ocorrência de sentenças matrizes finitas e infinitivas. A sua única opção será sentenças finitas.

Wexler observa que há uma variação entre as línguas em relação ao estágio do infinitivo opcional. Aparentemente, crianças adquirindo algumas línguas não passam por esse estágio, enquanto adquirindo outras passam. Se isto for correto, não há como dizer que esse estágio é universal. 
O autor então relaciona o estágio do infinitivo opcional com o parâmetro do sujeito nulo:

(32) O Sujeito Nulo / Generalização do Infinitivo Opcional Children in a language go through an OI stage if and only if the language is not an INFL-licensed null-subject language. (p. 56)

Segundo o autor, a criança passa pelo estágio do infinitivo opcional somente se estiver aprendendo uma língua que não é uma língua com sujeito nulo licenciado por INFL. Algumas línguas omitem o sujeito, mas ele não é licenciado por INFL, como é o caso de inglês em (33):

(33) Falante 1: John will never lose weight. He's eating too much. Falante 2: Yeah, isn't exercising enough either.

No contexto de (33), o falante 2 apaga o sujeito. Porém, esse sujeito não é licenciado por INFL. Ele é omitido por algum processo discursivo, segundo o autor.

Algumas línguas, como o polonês e o russo, omitem o sujeito, mas apresentam diferenças que interferem no estágio do infinitivo opcional. $\mathrm{O}$ russo, por um lado, omite sujeito, mas o sujeito nulo não é licenciado por INFL. Como ele não é licenciado por INFL, no período de aquisição a criança passa pelo estágio do infinitivo opcional. O polonês, por outro lado, assim como o italiano, tem sujeito nulo licenciado por INFL. Como o sujeito nulo é licenciado por INFL, a criança não passa pelo estágio do infinitivo opcional.

Wexler também relaciona línguas de sujeito nulo e línguas de sujeito não-nulo com a Restrição de Verificação Única que, segundo o autor, se aplica universalmente. Ele explica que em línguas de sujeito nulo, como o italiano, Agr é de natureza pronominal. Então Agr é D:

(34) Agr is D in a language if and only if the language is an INFL-licensed null-subject language. (p. 70)

Como Agr é D, não precisa do traço-D. Agr, nesse caso, licencia/identifica o sujeito nulo. Como somente $\mathrm{T}$ tem traço-D, o sujeito deve ir até 
[Spec, TP $]$ para verificar o traço-D de T. (35) seria, então, a estrutura de uma sentença finita de língua de sujeito nulo licenciado por INFL:

(35) a. Agr TNS $[\mathrm{D}]\left[_{\mathrm{VP}} \mathrm{DP} \mathrm{V} \ldots\right]$

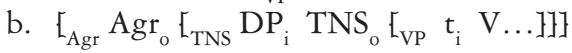

A Restrição de Verificação Única se aplica. De acordo com a Restrição, um único traço deve ser verificado. Como nessa língua temos um único traço-D para ser verificado, que é o de $T$, o sujeito vai para [Spec, TP] verificar o traço-D. Agr já é D e não precisa verificar este traço; assim, o DP fica em [Spec, TP]. A Restrição de Verificação Única se aplica vacuamente. Então, a estrutura infantil, como (35), é igual a do adulto.

Assim, a criança que adquire o italiano pode projetar simultaneamente Agr e T e não precisa se limitar às estruturas em (26c) e (26d); logo não haveria um estágio de "infinitivos matrizes opcionais" em italiano.

Nas línguas de sujeito não-nulo, em que $\mathrm{Agr}$ não é $\mathrm{D}$, isto é, Agr tem traço-D, temos a estrutura (29), repetida em (36):

(36) a. Agrs[D] TNS[D] $E_{\mathrm{VP}}$ DP $\left.\mathrm{V} \ldots\right]$

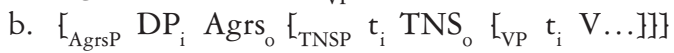

De acordo com a Restrição de Verificação Única, um único traço-D deve ser verificado. Se apenas o traço-D de T for verificado, a derivação implode. Sendo assim, a gramática infantil reestrutura a derivação, projetando ou TP ou AgrP, mas não ambos, como mostra (30). Dessa forma, um único traço-D será verificado e por isso temos a ocorrência das estruturas em (26).

A partir de nossos dados, observamos que a criança que está exposta ao $\mathrm{PB}$ apresenta um número muito pequeno de sentenças infinitivas matrizes. Observemos a Tabela 2: 
Tabela 2 - Freqüência de sentenças infinitas comparadas às sentenças finitas

\begin{tabular}{|c|c|c|c|c|c|}
\hline \multirow{2}{*}{ Idade } & \multicolumn{2}{|c|}{ SENTENÇA FINITA } & \multicolumn{2}{c|}{ SENTENÇA INFINITA } & \multirow{2}{*}{ Total } \\
\cline { 2 - 5 } & Aplicação & Freq. de Ocorrências & Aplicação & Freq. de Ocorrências & \\
\hline $\mathbf{1 ; 8}$ & 47 & $60,26 \%$ & 31 & $39,74 \%$ & 78 \\
\hline $\mathbf{1 ; 9}$ & 101 & $91 \%$ & 10 & $9 \%$ & 111 \\
\hline $\mathbf{1 ; 1 0}$ & 68 & $95,77 \%$ & 03 & $4,23 \%$ & 71 \\
\hline $\mathbf{1 ; 1 1}$ & 28 & $90,32 \%$ & 03 & $9,68 \%$ & 31 \\
\hline $\mathbf{2 ; 0}$ & 192 & $97,46 \%$ & 05 & $2,54 \%$ & 197 \\
\hline TOTAL & $\mathbf{4 3 6}$ & $\mathbf{8 9 , 3 4 \%}$ & $\mathbf{5 2}$ & $\mathbf{1 0 , 6 6 \%}$ & 488 \\
\hline
\end{tabular}

Num primeiro momento, no período de 20 meses, há um número relativamente alto de sentenças infinitivas $(39,74 \%$ contra $60,26 \%$ de sentenças finitas). Mas, já a partir de 21 meses, cai bruscamente o número de sentenças infinitivas proferidas pela criança. Vejamos o Gráfico 1:

Gráfico 1 - Percentagem do número de sentenças em cada período

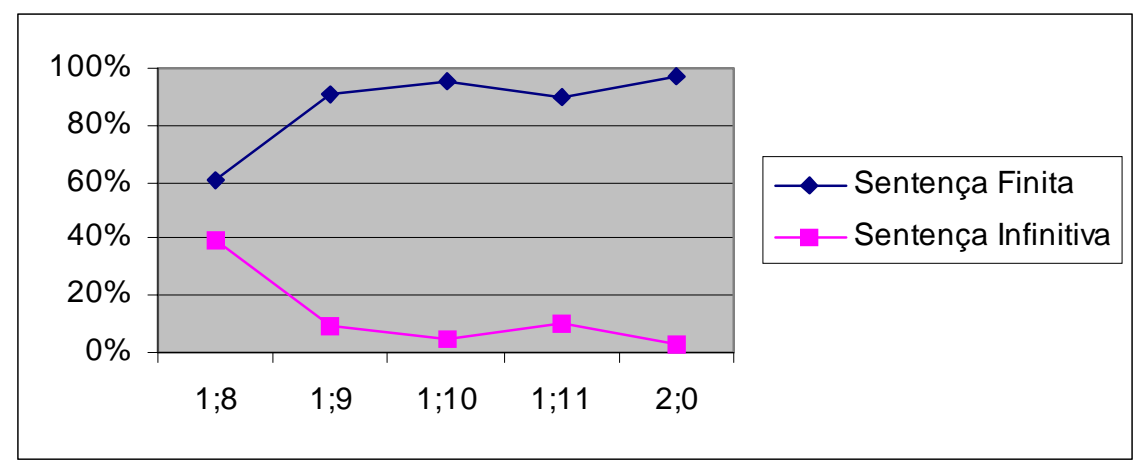

Como podemos observar no Gráfico 1, o número de sentenças infinitivas proferidas pela criança, no período de 1;8 meses a 1;9 meses de idade, sugere que há uma "queda brusca" de freqüência de infinitivas matrizes. Depois, segue-se um período mais ou menos estável, com baixa freqüência de infinitivas matrizes. Além disso, a quantidade de sentenças finitas proferidas é sempre maior do que $60 \%$ enquanto a de sentenças infinitivas é sempre inferior a $40 \%$. Podemos, assim, dizer que o PB apresenta um número reduzido de sentenças infinitivas proferidas pela criança: no total de sentenças, são 10,66\% contra 89,34\% de sentenças finitas. 
Comparando os dados do PB com os do inglês (estes fornecidos por Phillips 1995), observamos que há uma freqüência muito mais alta de sentenças matrizes infinitivas no inglês, no período de 1;5 meses a 2 anos, do que no PB. Observemos o Gráfico 2:

Gráfico 2: Proporção de raízes infinitivas no inglês

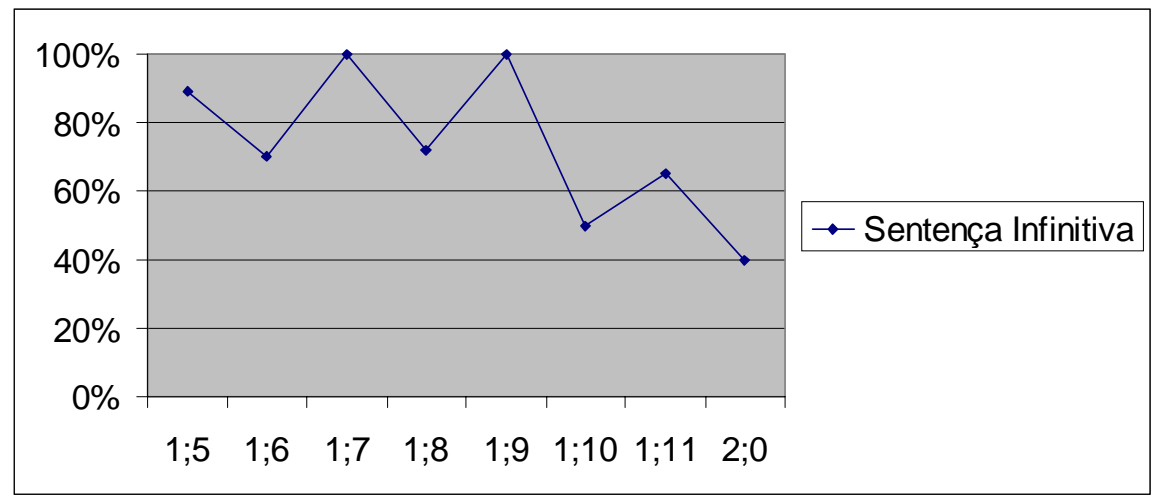

No período de $1 ; 5$ meses a 2;0 anos, a criança que está exposta ao inglês profere mais sentenças matrizes infinitivas (chegando a $100 \% \mathrm{em}$ alguns períodos) do que sentenças finitas.

As observações sobre o PB levam-nos a uma constatação interessante. Assumimos que Agr no PB é fraco no período de aquisição analisado. Observamos, na seção 3, que há violação de concordância, como mostra (18), repetido em (37):

(37) a. Ma: Onde cê vai? Vai na escola?

R: Vai. $(1 ; 09,8)$

b. A qué tilá tijama (Eu quero tirar pijama) $\quad(1 ; 10,23)$

Agr não foi acionado ainda com todos os seus traços relevantes. Assim, em (37), Agr não licencia o sujeito na sentença. Observamos, porém, que temos sentenças finitas como em (38):

(38) a. O vô sentá (Eu vou sentar)

b. Azudei (Ajudei) 
À primeira vista, parece que Agr licencia o sujeito das sentenças. Porém, seguindo Kato (2001), vamos supor que o sistema verbal da criança, neste período, seja unipessoal.

$\mathrm{O} \mathrm{PB}$, para nós, se comporta como o russo, ou seja, o sujeito não é licenciado por Agr. De acordo com a proposta de Wexler (1998), línguas que não têm o sujeito licenciado por INFL passam pelo estágio do infinitivo opcional. $\mathrm{O} P B$, porém, tem sujeito que não é licenciado por INFL, mas quase não apresenta o estágio do infinitivo opcional, como o italiano, apresentando apenas $10,66 \%$ de sentenças infinitivas no estágio do infinitivo opcional. Constatamos, assim, que a hipótese do Sujeito Nulo/Generalização do Infinitivo Opcional de Wexler, em (32), é muito forte, pois não se confirma para o PB.

Com relação à TP, Chomsky (1995) propõe que o seu traço-D seja universalmente forte. Assim, no PB, o traço-D de TP deve ser verificado antes de spell-out, em sintaxe visível. O que pode confirmar nossa hipótese é o fato de termos sentenças finitas com negação, como observado em (15), repetido em (39). Vejamos:

(39) Você um vai $(1 ; 10,23)$

Para (39), assumimos que o sujeito "nasce" em [Spec, VP] e vai para [Spec, TP]. O sujeito com traço-D [não-interpretável] vai para [Spec, TP] verificar o traço-D de T, que também é [não-interpretável].

Assim, assumimos que em torno de 1;8-2;0 anos, a criança que adquire o $\mathrm{PB}$ já projeta $\mathrm{T}$ e, além disso, $\mathrm{T}$ dispõe de um traço-D [não-interpretável], que deve ser verificado pelo sujeito via movimento para [Spec, TP]. Além disso, assumimos que no período analisado, Agr não é acionado nem para sentença finita nem para infinitiva. Portanto, apenas o traço-D de T será verificado; neste sentido, o PB satisfaz a Restrição de Verificação Única em (31). Como Agr não foi acionado ainda, o DP sujeito tem caso default que é nominativo, no PB.

Consideramos também que há dois períodos distintos para a gramática infantil no PB. Há um período em que T está presente, mas que tem núcleo default Presente, que é de 1;8 a 1;10 meses. Nesse período, analisamos as sentenças finitas e infinitivas como em (40): 


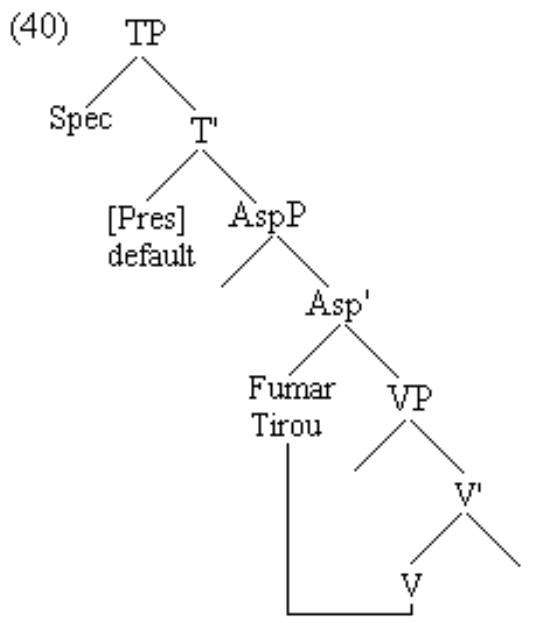

T serve de âncora temporal para Asp. Assumimos que o verbo não tem traços que necessitem de verificação, além dos verificados em Asp. Por isso, fica em Asp, conforme proposto por Kato (1995).

A partir de 1;10 meses, TP passa a ter como núcleo [Presente] ou [Passado]. Para sentenças finitas, do presente do indicativo, e infinitivas, temos a estrutura (41):

(41)

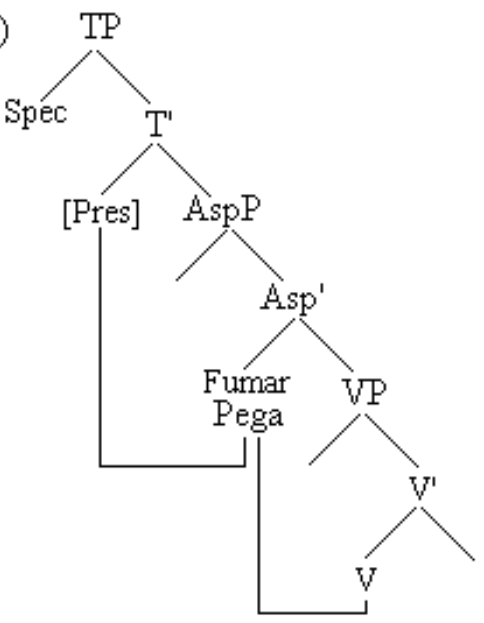


Propomos que as sentenças infinitivas têm traços de tempo [Presente] também. Isso porque observamos, em nossos dados, que em nenhum momento a criança utilizou a forma verbal infinitiva para se referir ao passado. Observemos o exemplo (42):

(42) M: Já cozinhou?

R: Pá galinha e po porquinho.

M: Isso! Prá galinha e pro porquinho! Agora você tá desligando o fogo. Isso mesmo! Bom, agora só tem um problema. Cadê a galinha e o porquinho, cadê? R: Cadê?

M: É.

R: Fajé uma coisa (baixo) (=Fazer uma coisa).

M: Eu quero saber onde está a galinha e o porquinho.

R: Não sei $(2 ; 00,20)$

Através do contexto de (42), podemos ver que, na sentença "Fajé" o tempo da sentença infinitiva é presente ${ }^{16}$.

Com relação à estrutura de (41), dizemos que o verbo e/ou auxiliar vai verificar o traço de tempo em $\mathrm{T}$, que é [Presente]. O sujeito, seja lexical ou nulo, com traço-D [não-interpretável] vai verificar o traço-D de T. Propomos que nesse período o sujeito nulo de uma sentença infinitiva seja PRO, conforme Kato (1995).

Kato (2001) assume que os pronomes têm caso default e que não precisam verificá-lo no sistema computacional. No entanto, propomos, conforme Wexler (1998), que PRO ou os pronomes lexicais verificam os traços-D de T em sintaxe visível. Vejamos (43), com sujeito PRO:

(43) a. José quer PRO esquecer completamente o episódio.

b. * José quer PRO completamente esquecer o episódio.

16 Ingham (1998) analisou as sentenças infinitivas em contexto presente e passado no inglês em crianças. Ele constatou que, no contexto de tempo passado, de 31 ocorrências apenas 02 eram sentenças infinitivas e 29 com morfologia marcada para o passado (-ed). Nos contextos de tempo presente, apareceram 55 sentenças infinitivas, de 57 ocorrências. O autor postula que as sentenças infinitivas não são formas sem tempo, isto é, raízes infinitivas. Ele as analisa como formas de tempo carregando [Presente]. 
Sportiche (1988) supõe que os advérbios têm posição fixa. Em (43a), sentença possível no $\mathrm{PB}$, o verbo esquecer verifica os traços de $\mathrm{T}$ em sintaxe visível, e por isso o verbo é alçado, ficando a ordem $V+A d v$. Sem o movimento do verbo, a oração é agramatical, como mostra (43b). Logo, o movimento do sujeito PRO é obrigatório. Então assumimos que em (43a) há movimento de PRO para verificação de traços-D de T.

Para as sentenças finitas no passado, assumimos que o traço de tempo [Passado] é verificado, como mostra (44):

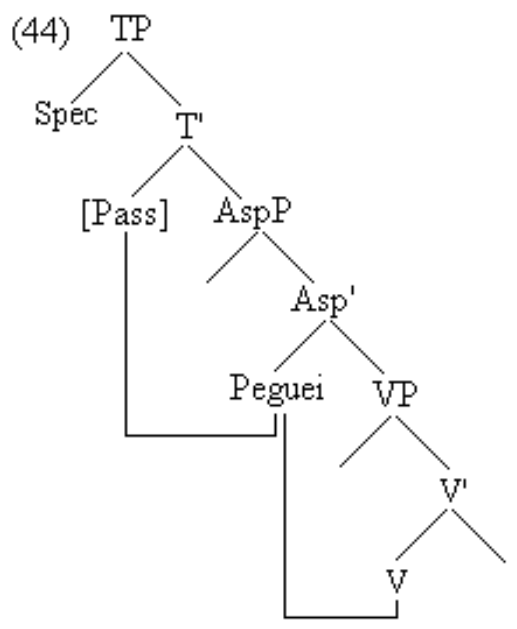

Em suma, assumimos que a criança trata o traço-D de DP como [nãointerptretável] no período analisado, como proposto por Wexler. Porém, diferente desse autor, propomos que Agr não é acionado no período inicial de aquisição. Isso acontece no $\mathrm{PB}$ porque temos Agr fraco nesse período. De acordo com Galves (1993), Agr é um traço que é adjungido a TP. Porém, assumimos que ele é uma categoria funcional independente.

Agr passa a ser acionado na gramática infantil a partir do momento em que a criança sair do sistema unipessoal, que será quando ela adquirir os pronomes fracos (pronomes livres, clíticos ou afixos). Para o PB, vamos assumir que o "trigger" que leva a criança do sistema unipessoal para um pluripessoal, e que conseqüentemente a leva a acionar Agr, seja a aquisição de flexão de número, isto é, da oposição singular/plural, conforme a proposto por Galves (1993). 


\section{Considerações Finais}

Nesse trabalho adotamos a hipótese continuísta fraca. Assumimos que há estágios diferentes para a gramática infantil, mas que não ferem a Gramática Universal. Assim, propomos que embora as categorias funcionais DP, CP, TP e AgrP estejam disponíveis desde sempre, Agr só é "acionado" em um período posterior. Neste sentido, adotamos a Hipótese da Aprendizagem Lexical de Clahsen (1989).

Assumimos que os itens lexicais são adquiridos no decorrer do tempo e que, com o aumento do léxico e do desenvolvimento dos sistemas de performance como memória e capacidade de processamento, a gramática infantil passa a ter a mesma forma da gramática adulta. Agr também é adquirido no decorrer do tempo. Por isso, no PB, é possível termos a coocorrência de sentenças matrizes finitas e infinitivas no estágio do infinitivo opcional. Agr é acionado quando o sistema verbal infantil passa de unipessoal para pluripessoal, conforme Kato (2001).

TP sempre é projetado. Num primeiro momento, o núcleo de TP tem traços de tempo default. Quando, porém, aparece o contraste temporal, que é com 1;10 meses na produção infantil analisada, TP passa a apresentar os traços dos tempos verbais [Presente] e [Passado].

Assumimos que os DPs, sejam nomes ou PROs, se movimentam em sintaxe visível para verificar o traço-D de TP, que é forte. Os verbos, sejam na forma finita ou infinitiva, também verificam traços de tempo em $T$ na sintaxe visível.

Observamos também que a hipótese de sujeito nulo/infinitivo opcional, proposta por Wexler (1998), não se sustenta para o PB. Consideramos que o PB tem Agr fraco e portanto os sujeitos nulos não são licenciados por ele. De acordo com Wexler, as línguas que não têm sujeito licenciado por INFL passam pelo estágio do infinitivo opcional. Porém, o PB quase não apresenta esse estágio, apresentando um total de 10,66\% de sentenças infinitivas.

Em outras palavras, o problema que o PB levanta para a generalização de Wexler é a seguinte:

(a) línguas como o inglês possuem um estágio de infinitivo opcional porque tanto Agr quanto T possuem um traço-D a ser verificado, e a res- 
trição de verificação única faz com que somente um deles, Agr ou T, possa ser projetado.

(b) línguas como o italiano não possuem este estágio porque somente $\mathrm{T}$ possui o traço-D; isto permite que ambos Agr e T possam ser sempre simultaneamente projetados (logo, não há estrutura em que só Agr seja projetado).

(c) o Agr do PB seria como o do inglês (já que, como em inglês, os sujeitos nulos do PB não seriam licenciados por Agr); entretanto, ao contrário do inglês, ele estaria "inativo" no estágio inicial e, por isso, a criança poderia projetar sempre Agr e T simultaneamente, sem violar a Restrição de Verificação Única de Wexler; e o resultado é que não haveria um estágio de infinitivo opcional em PB.

Recebido em dezembro de 2003 Aprovado em julho de 2005

E-mail: sanirc1@hotmail.com

\section{REFERÊNCIAS BibliográFiCAS}

Belletti, Adriana. 1990. Generalized Verb Movement. Turin: Rosenberg \& Sellier.

Chomsкy, Noam. 1995. O Programa Minimalista. Tradução de E. Raposo. Lisboa: Caminho, 1999.

Clahsen, Harald. 1989. Creole Genesis, the Lexical Learning Hypotesis and the Problem of Development in Language Acquisition. In: Pütz, Martin \& René Dirven. Eds. Wheels within Wheels. Frankfunt: Verlag: $55-79$.

Galves, Charlotte. 1993. O Enfraquecimento da Concordância no Português Brasileiro. In: Roberts, Ian. \& Kato, Mary (Eds.) Português Brasileiro: Uma Viagem Diacrônica. SP: Ed. da UNICAMP.

Guilfoyle, Eithne \& Nooman, Maire. 1988. Functional Categories and Language Acquisition. Mimeo.

Ingham, Richard. 1998. Tense without Agreement in Early Clause Structure. Language Acquisition, 7(1): 51-81.

Kato, Mary. 1995. Raízes não Finitas na Criança e a Construção do Sujeito. Caderno de Estudos Lingüísticos, 29: 119-136. 
. 1999. Os Frutos de um Projeto Herético: Parâmetros na Variação Intra-Lingüística. In: Hora, D. \& E. Christiano (Eds.) Estudos Lingüústicos: Realidade Brasileira. Rio de Janeiro: Idéia. . 2001. Nomes e Pronomes na Aquisição. Letras de Hoje, 36, no 3: 101-112.

Lopes, Ruth. 1999. Uma Proposta Minimalista para o Processo de Aquisição da Linguagem: Relações Locais. Tese de Doutorado. UNICAMP. . 2001. (Des)aprendizagem Seletiva: Argumentos em Favor de uma Hipótese Continuísta para a Aquisição. Letras de Hoje, v. 36, no 3 : 113-139.

MeIsel, Jürgen. 1994. Getting FAT: Finitess, Agreement and Tense in Early Grammars. In: MeIsel, Jürgen (Ed.) Bilingual First language Aquisition: French and German Grammatical Development, v. 7. Amsterdam, Philadelphia: John Benjamins: 89-129.

. 1997. Parâmetros na Aquisição. In: Fletcher, P. \& MACWhinney,

B. (Eds.) Compêndio da Linguagem da Criança. PA: Artes Médicas: 21-40.

PAlmieri, D. T. 1998. O Sistema-D nas Fases Iniciais da Aquisição da Linguagem. Letras de Hoje, 33, no 2: 151-158.

Phillips, C. 1995. Syntax at Age Two: Cross-Linguistic Differences. MIT Working Papers in Linguistics, 26: 325-382.

Pollock, Jean-Yves. 1989. Verb Movement, Universal Grammar, and the Structure of IP. Linguistic Inquiry, 20, no 3: 365-424.

RADFOrd, Andrew. 1990. Syntactic Theory and the Acquisition of English Syntax. Oxford: Blackwell.

. 1997. Estrutura Frasal e Categorias Funcionais. In: Fletcher, P. \& MacWhinney, B. (Eds.) Compêndio da Linguagem da Criança. PA: Artes Médicas: 394-415.

RizzI, Luigi. 1994. Some Notes on Linguistic Theory and Language Development: The Case of Root Infinitives. Mimeo.

Rubino, Rejane \& Pine, Julian. 1998. Subject-Verb Agreement in Brasilian Portuguese: What Low Error Rates Hide. Journal of Child Language, 25: 35-59.

Sportiche, D. 1988. A Theory of Floating Quantifiers and its Corollaries for Constituent Structure. Linguistic Inquiry, 19, no 3: 425-449.

Wexuer, Ken. 1998. Very Early Parameter Setting and the Unique Checking Constraint: A New Explanation of the Optional Infinitive Stage. Lingua, 106: 23-79. 